\title{
Publisher Correction: Heme enables proper positioning of Drosha and DGCR8 on primary microRNAs
}

\author{
Alexander C. Partin ${ }^{1,2}$, Tri D. Ngo1,2, Emily Herrell,2, Byung-Cheon Jeong ${ }^{1,2}$, Gary Hon ${ }^{1}$ \& Yunsun Nam (1) 1,2
}

Correction to: Nature Communications; https://doi.org/10.1038/s41467-017-01713-y, published online 23 Nov 2017.

The original version of this Article contained an error in Fig. 1. In panel d, the model on the right of the panel was incorrectly labeled '+Heme', and should have read '- Heme'. This has now been corrected in both the PDF and HTML versions of the Article.

Published online: $\mathrm{xx}$ xxx 2018

(c) Open Access This article is licensed under a Creative Commons Attribution 4.0 International License, which permits use, sharing, adaptation, distribution and reproduction in any medium or format, as long as you give appropriate credit to the original author(s) and the source, provide a link to the Creative Commons license, and indicate if changes were made. The images or other third party material in this article are included in the article's Creative Commons license, unless indicated otherwise in a credit line to the material. If material is not included in the article's Creative Commons license and your intended use is not permitted by statutory regulation or exceeds the permitted use, you will need to obtain permission directly from the copyright holder. To view a copy of this license, visit http://creativecommons.org/licenses/by/4.0/.

(C) The Author(s) 2018

\footnotetext{
${ }^{1}$ Cecil H. and Ida Green Center for Reproductive Biology Sciences and Division of Basic Reproductive Biology Research, Department of Obstetrics and Gynecology, University of Texas Southwestern Medical Center, Dallas, TX 75390, USA. ${ }^{2}$ Department of Biophysics, University of Texas Southwestern Medical Center, Dallas, TX 75390, USA. Correspondence and requests for materials should be addressed to Y.N. (email: yunsun.nam@utsouthwestern.edu)
} 